\title{
Temporal luminance summation effects in backward and forward masking'
}

CHARLES W. ERIKSEN

UNIVERSITY OF ILLINOIS

Two experiments tested six predictions derived from the assumptions underlying the luminance summation-contrast reduction explanation for certain instances of forward and backward masking effects. The predictions concerned the circumstances under which masking would occur and also that forward masking would be more extensive than backward masking under specified luminance arrangements. All six predictions were confirmed.

If a briefly presented visual stimulus is followed by a second stimulus within a short time lag, typically $100 \mathrm{msec}$. or less, there are circumstances under which the two stimulations interact. Impairment in perception may occur for the first stimulus (backward masking), the second stimulus (forward masking) or for both stimuli. Eriksen and Hoffman (1963) have advanced a luminance summation-contrast reduction hypothesis to account for certain instances of these forward and backward masking effects. Noting the evidence that the visual system integrates luminances over intervals of the order of $100 \mathrm{msec}$ (Clark \& Blackwell, 1959; Matin, 1962) or perhaps even longer (Kahneman \& Norman, 1964), Eriksen and Hoffman suggested that masking effects under certain experimental arrangements could be attributed to a reduced effective contrast for the stimulus figures arising from luminance summation between the two stimulations.

Backward and forward masking effects typically have been studied in Dodge-type tachistoscopes. A stimulus is presented to the eyes from one stimulus field and by means of a beam splitter the second stimulation comes from an independent field. If the stimuli consist of black figures on white grounds and the two figures do not fall on the same retinal areas, luminance summation-contrast reduction would occur in the following way. For the purposes of illustration assume the luminance from the ground is $10 \mathrm{~mL}$ and from the figure, $1 \mathrm{~mL}$ giving a contrast ratio of 10:1. If the first stimulus is presented for $10 \mathrm{msec}$. and followed immediately by the $10 \mathrm{msec}$. presentation of the second stimulus, the retinal areas on which the ground of the first stimulus falls would receive a stimulation equivalent to that from a source of $20 \mathrm{~mL}$. The retinal a rea corresponding to the figure would receive stimulation from $1 \mathrm{~mL}$ for the $10 \mathrm{msec}$. exposure, but since the second stimulation now presents ground on the area that had received figure in the first stimulation, this retinal area will have a stimulation from $10 \mathrm{~mL}$ added to the previous $1 \mathrm{~mL}$ stimulus. In terms of effective stimulation the contrast ratio of the figure in the first stimulus with its ground has been reduced from a ratio of 10:1 to less than 2:1. Essentially the same luminance summation effects would occur for the second stimulus.

This explanation of certain instances of masking effects has received strong support in several experimental studies (Eriksen \& Lappin, 1964; Eriksen \& Steffy, 1964; Thompson, 1966). It was the purpose of the present experiments to provide more definite tests of the luminance summation-contrast reduction hypothesis, and specifically to test its ability to predict circumstances under which backward and forward masking effects would and would not be obtained.

The luminance summation-contrast reduction explanation of forward and backward masking effects requires two assumptions about the visual perceptual system.

Assumption I. The accuracy of form detection or identification at brief exposure durations is, within limits, a function of the luminance contrast of the form with the ground; the higher the contrast the more accurate the detection or identification.

Assumption II. The visual system sums luminance from two or more successive stimulations distributed within a brief time interval of the order of $100 \mathrm{msec}$, with the completeness of the summation inversely proportional to the time interval between successive stimuli.

In the two following experiments six predictions have been deduced from these two assumptions and experimentally tested.

\section{EXPERIMENT I}

The validity of Assumption I has been well established for both long (Connor \& Ganoung, 1935) and for short exposure durations (Cobb \& Moss, 1928). Experiment I, however, was designed to assess the magnitude of the effect that contrast reduction has on a form identification task using luminance values in the range of those employed in masking studies and where the contrast reducing luminance is produced by one of the fields of the tachistoscope (veiling glare). In this sense Experiment I serves as a calibration for Experiment II.

Prediction: If black forms on white grounds are presented at brief durations in one field of a tachistoscope and the second field simultaneously presents an empty white ground, then form identification will be inpaired with the amount of impairment directly proportional to the luminance of the second field. 


\section{Subjects}

METHOD

Subjects were four undergraduate students (two females) who were paid volunteers. All Ss were highly practiced on perceptual recognition tasks and were run in this experiment following their completion of a very similar perceptual recognition experiment in which they had served 22 sessions.

\section{Apparafus and Procedure.}

A three-field Dodge-type tachistoscope, previously described (Eriksen \& Hoffman, 1963), was used. Two fields, F I and F II, were used as stimulus fields and a third field (FA) as an adaptation field containing the fixation point. The stimulus forms consisted of the capital letters $A, T$ and $U$, presented singly and requiring a forced-choice recognition response from $S$ after each presentation. The letters occurred randomly on the corners of an imaginary square of $1.25^{\circ}$ of angle centered on the fixation point. Previous research had indicated that these three letters were approximately equally discriminable and equally confusable one with another when presented at brief durations. Each letter subtended $0.2^{\circ}$ of arc on its maximum dimension. The letters had luminance of $0.009 \mathrm{~mL}$ and their ground $0.20 \mathrm{~mL}$ yielding a contrast ratio of $22: 1$. The adapting field, FA, was dark except for a faint glowing " $\mathrm{x}$ " fixation point, subtending $0.2^{\circ}$.

The $\mathbf{S}$ was instructed to fixate the $\mathrm{x}$ and when it appeared sharp and clear to press a trigger which presented the stimulus. This stimulus consisted of one of the three letters in F I presented simultaneously with a blank stimulus card which was illuminated for the same duration in F II. Four levels of F II luminance were employed, $0.00,0.09,0.20$ and $0.40 \mathrm{~mL}$. Within an experimental session all four F II luminance levels occurred equally often and were presented in a counterbalanced order. During two experimental sessions each $S$ made 50 judgments at each of the four F II luminance levels with 100 judgments being made in each experimental session. Prior to beginning the experimental sessions an exposure duration had been determined for each $\mathrm{S}$ that yielded between 80 and $85 \%$ forced-choice identification accuracy under the condition of the dark adapting field and no second field luminance. The exposure durations necessary for the four Ss to achieve 80 to $85 \%$ recognition accuracy under the condition of no second field luminance were $24,26,32$, and $35 \mathrm{msec}$.

\section{RESULTS AND DISCUSSION}

The test of the prediction is provided by the data in Fig. 1 which show the average percent identification of the three letters as a function of the log of contrast ratio. The function as a whole is negatively accelerated. When the contrast has reached a ratio of approximately $3: 1$, identification accuracy shows relatively little further increase with increases in contrast.

The data for each of the four Ss was consistent with the average results. Each $\mathrm{S}$ had a progressive increase in identification accuracy as the luminance of the F II stimulation decreased from 0.40 to $0.00 \mathrm{~mL}$, a result significant beyond the 0.001 level.

This result supports the experimental prediction. Strictly speaking, the data in Fig. 1 do not show the relation between form identification and contrast ratio per se since in these data total luminance is confounded with contrast ratio. This confounding, however, was deliberate. It is identical to the confounding which occurs in typical tachistoscope studies of masking. A demonstration of the effect of contrast ratio on form identification holding total luminance constant would not have been as germane to the luminance summationcontrast reduction explanation of masking effects.

\section{EXPERIMENT II}

The two assumptions underlying the luminance summation-contrast reduction explanation of masking effects were used to deduce the following five predictions:

1. The exposure duration necessary to achieve a given criterion of form identification will be least when the form stimulation is preceded and followed by at least $100 \mathrm{msec}$. of dark adapting field and greatest when the form stimulation is preceded, superimposed upon, and followed by an illuminated adapting field. A stimulation sequence in which the form is preceded by an illuminated adapting field which terminates with the onset of the stimulus and returns $100 \mathrm{msec}$. or more following termination of the stimulus will require an intermediate exposure duration to achieve the identification criterion.

2. Form identification will show little change as a function of the interstimulus interval (ISI) between form

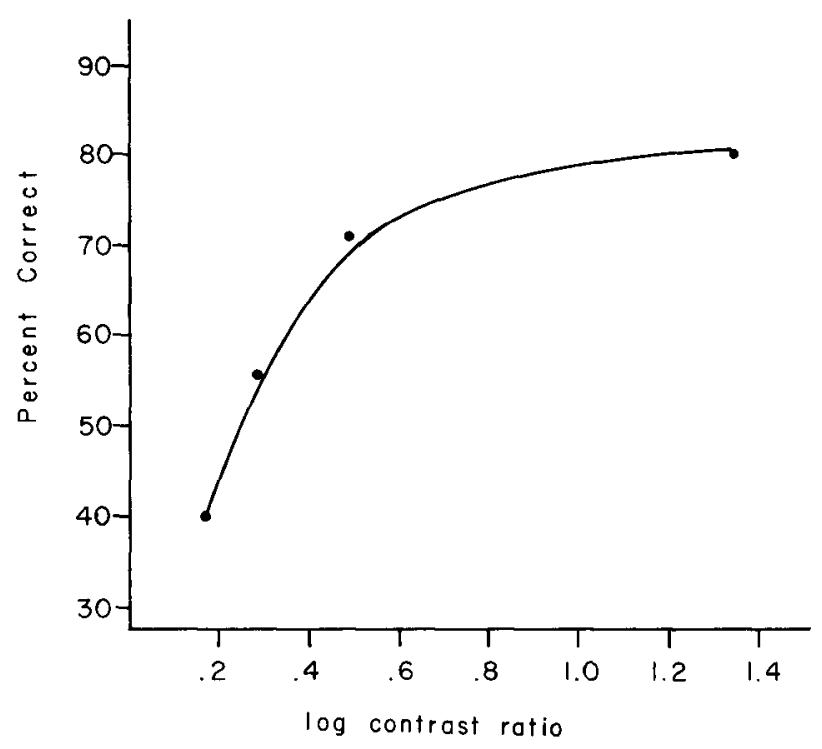

Fig. 1. Percent correct form identification as a function of the log of the ratio of the luminance of the ground to luminance of the figure. 
presentation and masking stimulus for either backward or forward masking sequences when the form and masking stimulations are superimposed upon a continuously illuminated adapting field whose luminance is relatively greater than those of the two stimulation fields. Under these conditions luminance summation is already occurring between adapting and form stimulation fields preceding, during, and following the form occurrence and the relatively small luminance of the masking field contributes little to further reduction of effective contrast.

3. Form identification will improve with increases in ISI between form and masking stimulus for the forward masking sequence and will tend to remain constant with the backward masking sequence when an adapting field whose relative luminance is greater than that of form and masking fields is employed in the following stimulation sequence: Adapting field terminates with onset of the first stimulation and remains off until $100 \mathrm{msec}$. or longer after termination of the second stimulation. Under this arrangement a form presented in the second stimulation (forward masking) will become increasingly more identifiable as the dark ISI between the masking flash and the onset of the form stimulation becomes greater. The longer the ISI the less luminance summation occurs between the form stimulus in F II and the luminance of the adapting and masking fields. A form presented in F I, however, (backward masking) is always preceded by the greater adapting field luminance and increasing delays of the masking flash in F II does little to increase identification since its relatively lesser luminance makes only a small contribution to effective contrast reduction for the $F$ I form even at short ISIs.

4. Both forward and backward masking effects will be marked when a dark adapting field and ISI are employed.

5. With a dark adapting field and ISI, forward masking will be greater in effect than backward masking. This prediotion is deduceable in part from the above two assumptions but it is in addition based upon the consideration that a form stimulation preceded by a masking flash has its contrast impaired right from its initial onset at short ISIs. On the other hand, a form stimulation followed by a masking flash has the full period of its duration plus the time of the ISI to act upon the visual system before its contrast is reduced by luminance summation from the masking flash.

\section{METHOD}

\section{Subjects}

Six practiced SB (three males) aged $19,20,22,27$, 39 and 44 years served as paid volunteers. All had normal or corrected to normal visual acuity.

\section{Apparafus and Procedure.}

The tachistoscope and stimulus forms were the same as employed in Experiment 1. All Ss were run under three experimental conditions. Under all three conditions two stimulus presentation sequences were employed. Under the first sequence (backward masking), one of the three letters was presented in F I followed at ISIs of $0,25,50,75$ or $100 \mathrm{msec}$. by the presentation of a uniform adapting field in F II.-Under the other sequence (forward masking), the letter form appeared in F II preceded by a flash of a uniform adapting field in F I at one of the five ISIs. After a stimulation sequence, $S$ was required to make a forcedchoice response as to which of the three letters had been presented. The test letter of $0.009 \mathrm{~mL}$ was, as in Experiment I, associated with a ground of $0.20 \mathrm{~mL}$.

The three experimental conditions differed in terms of whether the adapting field was light or dark and whether the ISI was lighted or dark. In Condition L the adaptation field with a luminance of $0.58 \mathrm{~mL}$ remained on continuously. A black $x$ served as fixation point, $0.2^{\circ}$ in size, and the stimulations from F I and F II were superimposed upon the adaptation field luminance.

Condition L-D also had a lighted adaptation field of $0.58 \mathrm{~mL}$ but here the adaptation field luminance terminated with onset of stimulation in F I and remained off until $300 \mathrm{msec}$. after the termination of stimulation in F II. Thus F I was always preceded by a luminance of $0.58 \mathrm{~mL}$ and F II, except at zero delay, was always preceded by a dark ISI and followed by a dark interval of 300 msec. duration,

In Condition $\mathrm{D}$ the adapting field was dark except for a faint glowing $x$ which served as a fixation point and was the same size as that employed in the other conditions. The ISI was also dark containing only the faintly luminous fixation point.

The Ss were run in a counterbalanced order through the three conditions. Prior to undertaking the experimental sessions each S received two 1-hr. practice sessions during which he identified the three stimulus letters at brief exposure durations. Each $S$ devoted six successive sessions to the $L$ and the $L-D$ conditions and 11 sessions to Condition $D$. The first session under a condition was devoted to obtaining a base level duration for that $S$ in that condition that would lead to approximately $55 \%$ identification accuracy of the three letters. This base level condition was run under the adapting field conditions obtaining for that condition but no masking flash occurred. To assure comparability of $F$ I and F II, half of the trials in random order contained the stimulus in F I and the other half in F II. Thus for Condition D, as an example, there was a dark adaptation field followed by the presentation of one of the three letters in either. F I or F II and a return to the dark adapting field. In Condition $L$ the $\mathrm{S}$ was confronted with the illuminated adapting field and a letter appeared in F I or F II superimposed upon the adapting luminance and then returned to only the adapting luminance. In Condition L-D the base level stimulation sequence consisted of the adapting luminance which terminated with the onset of a stimulus in F I or F II and $300 \mathrm{msec}$. after termination of this form a return to the adapting luminance. The exposuredara- 
Table 1. Summary of Luminance Values in Millilamberts for the Three Experimental Conditions

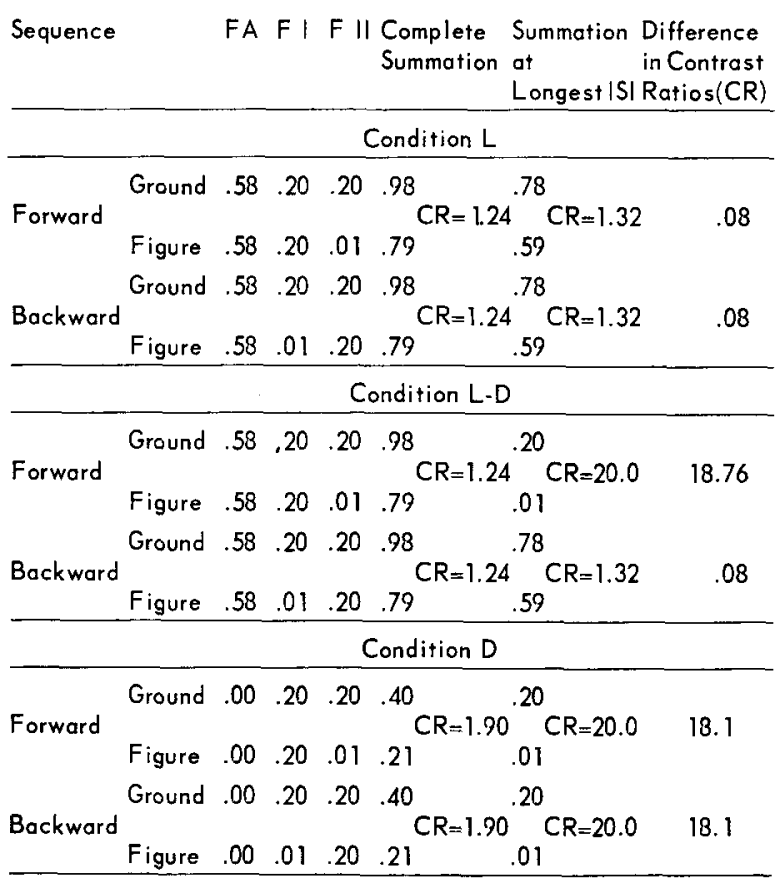

tion determined during the base level session was then used for a particular S for the F I and F II durations in the remaining experimental sessions under that condition.

In each of these five sessions $\mathrm{S}$ received six forward and six backward masking sequences or trials at each of the five ISI's. This resulted in a total of 30 identification trials for each $\mathrm{S}$ for the forward and 30 for the backward masking sequence at each of the five delay intervals per condition. An exception was Condition D where $\mathrm{S}$ served a total of 11 experimental sessions in order to provide greater sensitivity for detecting differences in backward and forward masking conditions. Here the number of identification trials was double that in the other two conditions. The beginning of each experimental session was preceded by a 10-min. dark adapting period and practice session.

The relation of the three experimental conditions to the predictions under test can be seen with the aid of Table 1. This table presents the figure and ground luminances by experimental condition for the different tachistoscopic fields and for the backward and forward masking sequences. The column labeled complete summation, shows the figure and ground luminances and contrast ratios that would obtain for the figure and ground if FA, F I and F II were activated simultaneously in the particular experimental condition. The next column, labeled minimum summation at longest ISI, shows the figure ground luminances and contrast ratios that would obtain for a condition if the ISI between form and masking flash was greater than the interval necessary for summation effects. (For simplicity in exposition, it is assumed that summation is complete if successive stimulations are separated by less than 1 msec.) The last column shows the difference in contrast ratios between optimum summation and minimum summation. This difference between contrast ratios within a condition provides an index of how much change in identification of the forms can be obtained by manipulating ISI. Alternatively stated, it provides an index of how much evidence of masking can be obtained for the condition.

From Table 1 it can be seen that the maximum reduction in contrast that can exist for the retinal image would occur when all three tachistoscope fields were simultaneously illuminated. Here the contrast ratio would be approximately 1.24 . In Condition $\mathrm{L}$, which tests prediction 2, the stimulation is always superimposed upon the adapting field luminance. If the form occurs in F I, the retinal areas receiving the ground will be stimulated by a luminance of $0.78 \mathrm{~mL}$ and the areas receiving the figure will receive 0.59 for a contrast of 1.32. Even if the F II masking flash occurs at zero ISI, it changes the contrast ratio only to 1.24 . From Fig. 1 of the previous experiment it can be seen that such a slight decrease in effective contrast would have only a very slight effect upon form identification accuracy. In Condition L-D delaying the form stimulus in F II beyond the summation interval can lead to a marked increase in contrast ratio. Here if all three fields were simultaneously activated the ground would have a stimulation value of $0.98 \mathrm{~mL}$ and the form would have 0.79 , yielding a contrast ratio of $1: 24$. However, delaying the presentation of the form in the F II stimulation beyond the summation interval results in an effective stimulus where the ground has $0.2 \mathrm{~mL}$ and the form image $0.01-a$ contrast ratio of $22: 1$. Under the backward masking sequence in this condition even with long ISIs between masking and form presentation there is little change in effective contrast ratio. Here the luminance relations remain essentially as in Condition L. It can also be seen that in Condition D contrast ratio will vary markedly for both the forward and backward masking sequence as the ISI between F I and $\mathrm{F}$ II varies.

\section{RESULTS}

The first prediction pertained to the exposure duration required for $55 \%$ recognition accuracy of the forms when no masking stimulus was used. The base level data for the three conditions provide a test of this prediction. Condition $\mathrm{L}$ would be expected to require the longest duration since the forms were presented superimposed upon a brighter luminance from the adapting field. Condition $\mathrm{D}$ would require the shortest duration since the form was preceded and followed by a dark adapting field. An intermediate duration would be predicted for Condition L-D since the form followed immediately after the termination of the relatively brighter adapting field but was followed by $300 \mathrm{msec}$. of dark interval. In Condition $L$ the mean exposure duration for the six Ss was $75 \mathrm{msec}$, in Condition L-D, 

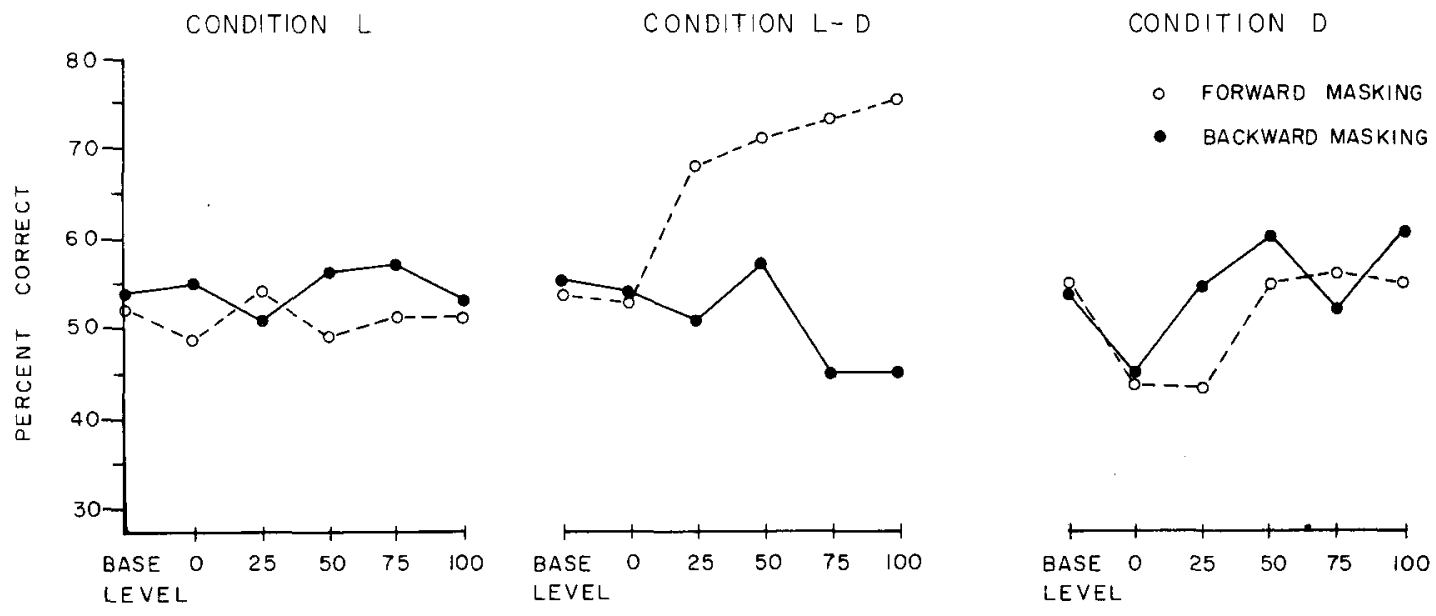

INTERSTIMULUS INTERVAL IN MILLISECONDS

Fig. 2. Percent correct form identification as a function of forward and backward masking sequence and experimental conditions.

42, and in Condition $D, 21$. The data for each of the six Ss followed the same ordering across conditions as the means, a result significant beyond the .001 level.

Before examining the remaining predictions in detail, the number of correct form identifications were analyzed in a four-way classification analysis of variance (Ss, ISIs, forward and backward masking sequence, and experimental conditions). Of the four main effects only conditions failed to achieve significance at the .01 level. All the two-way interactions except those involving the $S$ variable were significant at or beyond the .01 level. There was, however, a significant $S$ by condition interaction and the triple interaction between ISIs, backward and forward masking and conditions was significant beyond the .05 level. The significant $S$ effect and $\mathrm{S}$ by condition interaction, was anticipated due to inability to match Ss exactly at a base level of $55 \%$ identification accuracy within and across conditions.

The nature of these significant effects and interactions can be seen in Fig. 2. Here identification accuracy is shown as a function of the backward and forward masking sequence and ISIs for each of the experimental conditions. The graphs also show the base level performance by stimulus fields which was obtained under the adapting field specifications for the experimental condition but without the masking flash.

The data from Condition $L$ provide information on prediction 2 that for both forward and backward masking sequences, form identification would remain relatively constant as ISI varied. The data from this condition support the prediction. There is none of the usual evidence of masking. Form identification remains at essentially the base level irrespective of whether the form is preceded or followed by the relatively dim flash of the masking field.

The data from the L-D condition provide a test of prediction 3 . For the backward masking sequence the form presented in F I is always immediately preceded by the relatively brighter adapting field. The relatively dimmer masking stimulus in F II, as was seen in Table 1, has little effect on further reducing the effective contrast for the form presented in F I even at zero ISI. As a consequence, form identification for the backward masking condition was expected to remain at the base level condition. As is seen in Fig. 2, this result essentially obtains although there is an unexplained decrease in form identification under this sequence at the ISIs of 75 and $100 \mathrm{msec}$.

For the forward masking sequence in Condition L-D the form stimulus appears in F II preceded by the relatively brighter adapting field and the masking stimulus in F $I_{0}$ As ISI increases, there is an increasing dark period preceding the occurrence of the form in F II. With the longer dark ISIs luminance summation from the adapting and FI masking stimulation decreases and there is an increase in effective contrast for the F II form with a corresponding increase in correct identification. In the graph identifiability of the form under the forward masking sequence rises from the base level to an asymptote in the neighborhood of 75 to 100 msec. of ISI.

Prediction 4 stated that both forward and backward masking effects would be evident where the adapting field and ISI were dark, the arrangement that obtained in Condition D. As is seen in Fig. 2, pronounced masking effects are found for both the forward and backward sequence out to an ISI of at least $75 \mathrm{msec}$. For both sequences identification drops from the base level with the introduction of the masking flash and then rises gradually to an ISI in the neighborhood of $75 \mathrm{msec}$.

Prediction 5 stated that forward masking effects under the circumstances obtaining in Condition D would be more extensive than backward masking effects. The functions shown in Fig. 2 are consistent with this prediction. Identification is poorer with the forwardmask- 
ing sequence at all ISIs less than $75 \mathrm{msec}$.

As was pointed out in the procedure, twice as many observations were taken under this experimental condition, $D_{2}$ in order to provide a more sensitive test of differences between forward and backward masking sequences. To determine whether the differences between these sequences in this condition were statistically reliable, the data for this condition, using only the ISI intervals of $50 \mathrm{msec}$. or less, were subjected to a three-way classification analysis of variance (Ss, ISIs, backward and forward masking sequence). Significant at or beyond the .01 level were the main effects due to Ss, to lags and, of major interest, the interaction of lags by backward and forward masking sequence.

\section{DISCUSSION}

The results of these two experiments provided rather striking confirmation for the six predictions derived from the assumptions underlying the luminance summation-contrast reduction hypothesis. The validity of these two assumptions is attested to not only by their ability to predict the circumstances under which masking effects will occur and the shapes of the particular functions but also from a much broader range of visual perceptual research. The summing of luminances over short time durations is indicated not only in the work on critical flicker fusion but in the well established Bunsen-Roscoe law. Directly relevant to luminance summation and the effect of contrast reduction on form recognition is the recent work of Thompson (1966). He found that luminance summation occurred over an interval of nearly $100 \mathrm{msec}$. and he was able to directly relate form recognition to the attendant contrast reduction that occurred from the summation. Also, Zuercher (1965) found that the identification of letter forms was a direct function of the amount of light energy that occurred within an 80 to $100 \mathrm{msec}$. interval, irrespective of whether the light energy was divided into from 2 to 12 separate pulses distributed over the interval.

While luminance summation with attendant contrast reduction ior forms would seem to be a basis for certain backward and forward masking effects, there is also evidence that other processes may be involved in visual masking. For example, Alpern (1953), Averbach and Coriell (1961), and Eriksen and Collins (1964; 1965) have obtained masking effects under circumstances where luminance summation was eliminated or greatly reduced. But the luminance summation-contrast reduction effect seems well enough supported so that careful experimenters should insure that in future experiments it is not confounded with other masking effects they are attempting to study. Other masking processes can be more easily confirmed and identified if experiments are designed to eliminate or reduce luminance summation.

While the present experiments used black figures on white grounds and a blank white field as a masking stimulus, it is to be noted that luminance summation effects are not limited to these stimuli and masks. One can readily deduce the patterns of luminance summation and attendant contrast changes when overlapping stimuli and patterned stimuli are used as the masking stimulus. As Schiller and Smith (1965) have found, masking effects are apt to be much more extensive when a black and white patterned masking stimulus is employed. When a masking stimulus consisting of a pattern of black dots or squares on a white field is employed, the parts of the test form or letter thatoverlapblack areas in the masking field come through to the eye with unimpaired contrast. Those parts that do not overlap have their contrast reduced. As a result one gets a very irregular random-type form in perception which can lead to confusions with other alternatives in the stimulus set. This would appear to pose a more difficult identification problem than when a blank white mask field is used and the test form appears only more faint but relatively undistorted.

\section{References}

Alpern, M. Metacontrast. J. Opt. Soc. Amer., 1953, 43, 648-657. Averbach, E., \& Coriell, A. S. Short-term memory in vision. Bell Sys. tech. J., 1961, 40, 309-328.

Clark, W. E., \& Blackwell, H. R. Relations between visibility thresholds for single and double pulses. U. Mich. Engng. Res. Inst. Proj. Mich. Rep., 1959, No. 2144-343-T.

Cobb, F. W., \& Moss, F. K. The four variables of the visual threshold. J. Franklin Inst., 1928, 205, 831-847.

Connor, J. P., \& Ganoung, R. E. An experimental determination of the visual thresholds at low values of illumination. J. Opt. Soc. Amer., 1935, 25, 287-294.

Eriksen, C. W., \& Collins, J. F. Backward masking in vision. Psychon. Sci., 1964, 1, 101-102.

Eriksen, C. W., \& Collins, J. F. A reinterpretation of one form of backward and forward masking in visual perception. $J$. exp. Psychol., 1965, 70, 343-351.

Eriksen, C. W., \& Hoffman, M. Form recognition at brief durations as a function of adapting field and interval between stimulations. J. exp. Psychol., 1963, 66, 485-499.

Eriksen, C. W., \& Lappin, J. S. Luminance summation-contrast reduction as a basis for certain forward and backward masking effects. Psychon. Sci., 1964, 1, 313-314.

Eriksen, C. W., \& Steffy, R. A. Short-term memory and retroactive interference in visual perception. J. exp. Psychol., 1964, 68, 423-434.

Kahneman, D., \& Norman, J. The time-intensity relation in visual perception as a function of observer's task. J. exp. Psychol., $1964,68,215-220$.

Matin, L. Binocular summation at the absolute threshold of peripheral vision. J. Opt. Soc. Amer., 1962, 52, 1276-1286.

Schiller, P. H., \& Smith, M. C. A comparison of forward and backward masking. Psychon. Sci., 1965, 3, 77-78.

Thompson, J. H. What happens to the stimulus in backward masking? J. exp. Psychol, in press.

Zuercher, J. D. Visual recognition as a function of an intermittent stimulus varied over time. Unpublished doctoral dissertation, University of Illinois, 1965 .

\section{Note}

1. This investigation was supported by Public Health Service research grant MH-1206 and a Public Health Service research career program award $\mathrm{K} 6-\mathrm{MH}-22,014$.

(Received in the Editorial Office January 13, 1966.) 